carcinogens, are nutritionally essential trace minerals, which is not mentioned. Either there is a threshold below which such substances are not carcinogenic, or there is no threshold, and therefore life is carcinogenic, but we cannot deny both of these possibilities. But the authors repeatedly emphasise that there is no safe dose of any carcinogen, and, on page 211 , they say " "Life' is not carcinogenic". I disagree. First, there must be a threshold for certain carcinogenic stimuli (such as iodine deficiency in rats). Second, life can be carcinoginic because mutations accumulate in DNA during ageing, including mistakes in DNA replication and

Appendix A says that caffeine "may cause miscarriages or birth defects". Such a statement is pointless without being quantitative and is also irresponsible and sensational. The final chapter is "The Solution to the Problem", emphasising pages 224-232) "Personal Involvement in the Regulatory Process”. those caused by environmental mutagens.

Leading experts in the field of environmental cancer are far less dogmatic than are the EDF sextet. John Higginson concludes (Science, 205, 1363; 1979), that the manner in which people live - diets, dress, sexual and child bearing patterns, and especially tobacco and alcohol consumption - account for the great variations in cancer rates in different countries, and may be far more important than chemical pollutants. He reports that cancer patterns within Europe show no correlations with industrialisation. $\mathrm{He}$ says... "people would love to be able to prove that cancer is due to pollution or the general environment. It would be so easy to be able to say let us regulate everything to zero exposure and we have no more cancer. The concept is so beautiful that it will overwhelm a mass of facts to the contrary".

Thomas H. Jukes is a Professor in Residence in the Department of Biophysics and Medical Physics, and a Lecturer in Nutritian Sciences at the University of California at Berkeley.

\section{Potency of interferon}

\section{C. Burke}

The Interferon System. By W. E. Stewart. Pp.421. (Springer: Wien and New York, 1979.) DM98; \$53.90.

THIs book is a comprehensive review of the entire interferon literature, and fills a considerable gap. The last single-author book on interferon appeared in 1969 and the last multi-author book in 1973. Since then a number of specialist reviews have appeared, but no-one until now has had the courage and energy to tackle a survey of the field single-handed. The author is to be congratulated on a fine achievement, and the book will be greatly used.

As the author points out, interferon has received considerable recent publicity in both the scientific and popular literature as a potentially useful antiviral and antitumour agent. Its potential as an antiviral agent has indeed been obvious ever since its discovery by Isaacs and Lindenmann in 1957, but it has been slow to realise it. In retrospect, this is partly because quite inadequate amounts of interferon were available for the early trials, and partly because we did not choose the most suitable infections for treatment.

Attention has now swung away from treatment of respiratory infections to such life threatening conditions as chronic active hepatitis and viral infections of immunosuppressed or immunodeficient patients. Here useful and encouraging trials are taking place. It is, however, the potential use of interferon as an anti- tumour agent that has attracted most recent attention, for, stimulated by a careful ongoing trial against osteogenic sarcoma in Sweden, there have been several wellhuman cancer in the USA. In addition, interferon has emerged as a cellular modulatory factor, affecting the growth of cells, the immune system and the growth of tumours; and the mechanism by which it is produced is being investigated as a model for gene derepression in eukaryotes.

The book is therefore timely. Interferon research has continued apace and we greatly need a good critical summary. The book will be invaluable for those who are starting research in the area, but also for those who, like the reviewer, have been in the field a long time but who cannot remember who did what and when. The book has a complete coverage discussing topics as disparate as the structure of doublestranded RNAs, the genetics of the interferon system, the pharmacokinetics of interferon, and its role in normal recovery from virus infection, in addition to the trials as an antiumour and antiviral agent. The bibliography contains nearly 2500 references and the author has compiled 18 tables, many of which summarise information which has not previously been drawn together - for example, a compilation of the properties of type II interferon and a seven-page table of the cross-species activities of interferons.

However, the book is more than a compilation, for the author does not hesitate to comment, often constructively. There are, for example, interesting discussions of the different hypotheses which have been advanced to explain the mechanism of virus induction of interferon, of the mechanism of superinduction, and of the various schemes for interferon purification. publicised reports of its activity against

\section{SCIENTIFIC BOOKSHOP}

H. K. LEWIS can supply works in all branches of Pure and Applied Science. Catalogues on request. Please state interests.

\section{SCIENTIFIC LENDING LIBRARY}

Annual Subscription from $\mathbf{£ 7 . 5 0}$. (Available in U.K. only)

Reduced rates for multiple subscriptions.

Prospectus post free on request.

Quarterly List of New Books and new editions added to the Library sent post free to subscribers regularly.

\section{H. K. LEWIS \& Co. Ltd. 136 GOWER STREET, LONDON, WC1E 6BS}

Telephone: $01-3874282$

Telegrams: "Publicavit,

London, WC1E 6BS."

Circie No. 59 on Reader Enquiry Card.

Bring Your Library

Up-to-Date With This

ANS Edition...

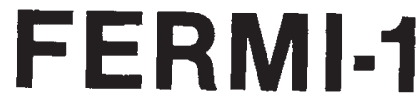

\section{NEW AGE FOR NUCLEAR POWER}

Historical Development of

Nuclear Energy

In the United States

454 pages 6 " $\times 9$ "

Hardbound ... $\$ 27.80$

American Nuclear Society

555 North Kensington Avenue

LaGrange Park, IL 60525 USA

Please take my order for book(s).

Payment in full enclosed

Bill me and I accept postage and handling charges

NAME

ORG.

STREET

CITY

STATE

Circle No. 58 on Reader Enquiry Card 
Unhappily, in spite of the wide usefulness the book will undoubtedly have, the book is flawed by personal animus against a few scientists, and by occasional lapses into slangy diction. Cells do not "quit" making interferon, and sentences like "Studies on the mechanisms controlling the transcription and translation of interferons will likely soon enable better artificial regulation of these mechanisms, to provide sufficient interferon messenger RNA to allow its retrocopy into prokaryotic cells from which clones interferon can become truly abundant"' make one gasp.

D. C. Burke is Professor of Biological Sciences at the University of Warwick, Coventry, UK. He has worked on interferon since April, 1957, starting to collaborate with the late Dr Alick Isaacs and Professor Jean Lindenmann a month or two after the initial discovery.

\section{Elements of cloning}

\section{Marie A. DiBerardino}

Cloning: A Biologist Reports. By R.G. McKinnell. Pp. 130. (University of Minnesota Press: Minneapolis, 1979.) $\$ 8.95$.

PROFESSOR MCKINNELL terminates his book with the following three sentences in the epilogue: "Cloning is one of many experimental procedures that provide information that may help in solving problems such as cancer and ageing. That is the why of cloning. And to assist people in understanding that "why - i.e., the rationale of cloning - I have written this book". The author has accomplished his objective. He is a research biologist who has carried out nuclear transplantation studies (one form of cloning) directed towards understanding normal cell differentiation, cancer, immunobiology and ageing. Few scientists possess both the authoritative background and literary talent to communicate accurately the relevance of bench-work research to its future potential for solving biomedical problems. McKinnell, however, manages to convey the significance of this basic research to the non-scientist.

McKinnell begins his book by correcting erroneous and inflamnatory statements about cloning and points out that the cloning of plants has been in practice for over 4000 years and has served to enrich man with beauty and food. This process is achieved by means of asexual reproduction resulting in a genetic replicate of the parent, whereas sexual reproduction involves the combination of genes from two parents and thus produces an individual containing a diversity of genetic traits.

The author then embarks on a description of classical animal studies carried out during the late nineteenth and early twentieth centuries that laid the ground-work for the amphibian cloning experiments. During this period there occurred a fusion of the disciplines of genetics, embryology and cytology; and the central problem that occupied these early scientists was the theory of nuclear equivalence. They sought to determine whether the diverse specialised cells of an organism retain the same set of genes as the nucleus of the fertilised egg. The earliest scientists recognised the stability of the differentiated state, that is, liver remains liver even if a person lives beyond ninety years, as pointed out by McKinnell. To explain this phenomenon, a theory of genetic differences among the progeny of the zygote nuleus was proposed by Weismann to account for the origin of cell diversity and stability. However, this proposal was refuted at least for nuclei from the earliest stages of development by the primitive cloning experiments of Loeb in the sea urchin and later of Spemann in the salamander. Finally, in 1952 "a fantastical experiment" termed and proposed by Spemann, was accomplished by Briggs and King. They sought to extend the primitive cloning experiments and transplanted a living nucleus from a cell from a frog blastula embryo, a day old, into a frog egg whose own nucleus had been removed surgically. The blastula embryo contained thousands of cells all derived from a zygote nucleus, but these blastula nuclei were still capable of promoting eggs to develop into normal larvae and eventually in later studies into normal frogs, demonstrating that the donor nuclei contained a set of genes equivalent to the zygote nucleus. This prototype experiment has been repeated many times in various amphibian species throughout the world, and it is now well established that many nuclei from early embryonic stages are totipotent. The theory of nuclear equivalence is still the central problem of developmental genetics today. The cloning studies have been most extensively carried out in two amphibian forms - the leopard frog, Rana pipiens, and the South African frog, Xenopus laevis. Cloning experiments have shown that during the course of embryogenesis, transplanted nuclei become progressively restricted in their ability to promote normal development of the eggs; and so far no nucleus of an adult cell has programmed an egg to develop normally. Despite this, a most extraordinary result does occur when nuclei from adult cells are cloned. A small percentage of eggs develops through embryogenesis to early larval stages and contain all the cell types and tissues of a larva, indicating that an extensive gene complement is still present and functional. Similarly, frog nuclei from adult kidney tumours when transplanted to eggs also lead to the formation of larvae. This subject, an area in which the author has made important research contributions, is discussed at some length. He points out that the formerly held pessimistic view of the irreversibility of cancer has been alleviated by these and other experiments. Thus, although important strides have been made in studying problems of normal cell differentiation and cancer, much more needs to be done in the future. McKinnell proposes: "If more were known about cancer-cell genetic material and about regulating its differentiated state, there would be the rational hope that a cancer chemotherapeutic agent could be devised that would regulate differentiation of these malignant cells"'.

Although amphibian cloning has been the most extensively studied among multicellular organisms, there has also been some work done on insects and fish. However, attempts at mammalian cloning have so far not been successful. But McKinnell points out that many of the techniques are available and the expectation that the remaining ones will be solved is encouraging. Cloning of farm animals may have agricultural advantages - for example, one could select for outstanding milk production, quality of wool, disease resistance, and so on; and this approach would be extremely faster than selective breeding for genetic traits.

Finally, McKinnell reviews some of the concepts of human cloning theorised by science-fiction writers, philosophers, theologians and lawyers. He addresses himself as a biologist and expert cloner to the social, ethical and biological problems inherent in their suggestions. Among his various refutations he emphasises that cloning may result in genetic replicates but not carbon copies, a widely misunderstood point. He also points out that species are successful due to the diversity of genes available through sexual reproduction, and so cloning is not a sound reproductive method.

McKinnell has performed an important service for both scientists and nonscientists in his well balanced and critical review of cloning, and at an appropriate time when both groups need an accurate account of the applications of nuclear transplantation studies to the biomedical sciences, in order to evaluate the erroneous and exaggerated notions of cloning that have been perpetrated upon the public. This book will be especially invaluable to non-specialists. A series of superb illustrations, together with the clarity and simplicity of prose, will permit the nonspecialist to understand the basic elements of cloning and its biomedical implications.

Marie A. DiBerardino is Professor of Anatom at the Medical College of Pennsylvania, Philadelphia. Dr DiBerardino began her nuclear transplantation studies with the originators of cloning (Briggs and King) during the 1950s. 